\title{
Study of wire tool-electrode behavior during electrical discharge machining by vibroacoustic monitoring
}

\author{
Sergey N. Grigorieva, Mikhail P. Kozochkin, Elena Yu. Kropotkina \\ AND ANnA A. OKunKova \\ Moscow State University of Technology "STANKIN", 1 Vadkovsky per., Moscow GSP-4, 127994, Russian Federation
}

Received 9 November 2016, Accepted 12 December 2016

\begin{abstract}
In the current study, the full research of wire electrode behavior during electrical discharge machining is presented. The analysis of the work preparation processes gave a possibility to clarify the main parameters (factors) influencing on the final characterization of the obtained object. For the experiments, the system MACHINE-TOOL-WORKPIECE was established. The system was equipped by vibro-acoustic accelerometers to register the signals during processing. Processing of two work pieces from stainless steel $12 \mathrm{Kh} 18 \mathrm{~N} 10 \mathrm{~T}$ (analogue AISI 321) and aluminum alloy D16 gave the characterization of the material behavior. Further, the analysis of SEM pictures gave the important data about the character of wire tool wear during processing. The two main natures of the wire tool wear were recognized. The scheme of the wire tool wear for rough and finish cuttings was developed to demonstrate the results of the research.
\end{abstract}

Key words: Wear / electrical discharge machining / wire electrode tool / vibro-acoustic diagnostic / SEM analysis

\section{Introduction}

Nowadays Electrical Discharge Machining (EDM) is one of the most developed and essential non-traditional machining method [1-3]. The application of EDM is always necessary, when the material is conductive, but its hardness does not give a possibility to apply on of the traditional cutting methods. Meanwhile the nature of the processes during EDM is not enough clarified nowadays $[4,5]$.

The difficulties in the research of the method is a question of the inability for the optical control during machining $[6,7]$.

In the conditions of the real manufacturing processes, the tool wear monitoring is conducted by an experienced operator "by ear". The operation is accompanied by a specific "buzzing" sound, which grows with the cutting speed and with the intensity of machining, and it characteristically changes when obstacles appear in the path of the wire-electrode, having the form of hollows and densities of machined material, and in case of a severe wear and a subsequent break of the tool-electrode [7].

In some scientific articles [8-15], the authors address the issues of monitoring of the electrical discharge machining process and examination of the surface of the

${ }^{a}$ Corresponding author: science@stankin.ru processed material, however, the study of wear of the wire tool-electrode itself during machining is still insufficiently covered.

There are two types of process operations monitoring, which can be conducted during machining: optical and vibroacoustic. The vibroacoustic method as applied to the electrical discharge machining monitoring is more preferable because there are no visual contact in the work zone when performing process operations [16]. The vibroacoustic method was mostly used for "cutting" operations, such as turning, milling, grinding, and it was not never before used for the purposes of electrical discharge machining [17-19]. The authors propose to broaden the application of the vibroacoustic method of process operations monitoring for study the patterns of the wire tool-electrode wear during electrical discharge machining. The research is aimed at fundamental study of the electrical discharge machining process with consideration of possible subsequent practical application of such type of diagnostics for solving the practical tasks in the field of electrical discharge machining.

\section{Experimental setup}

The experimental setup is presented in Figure 1. 


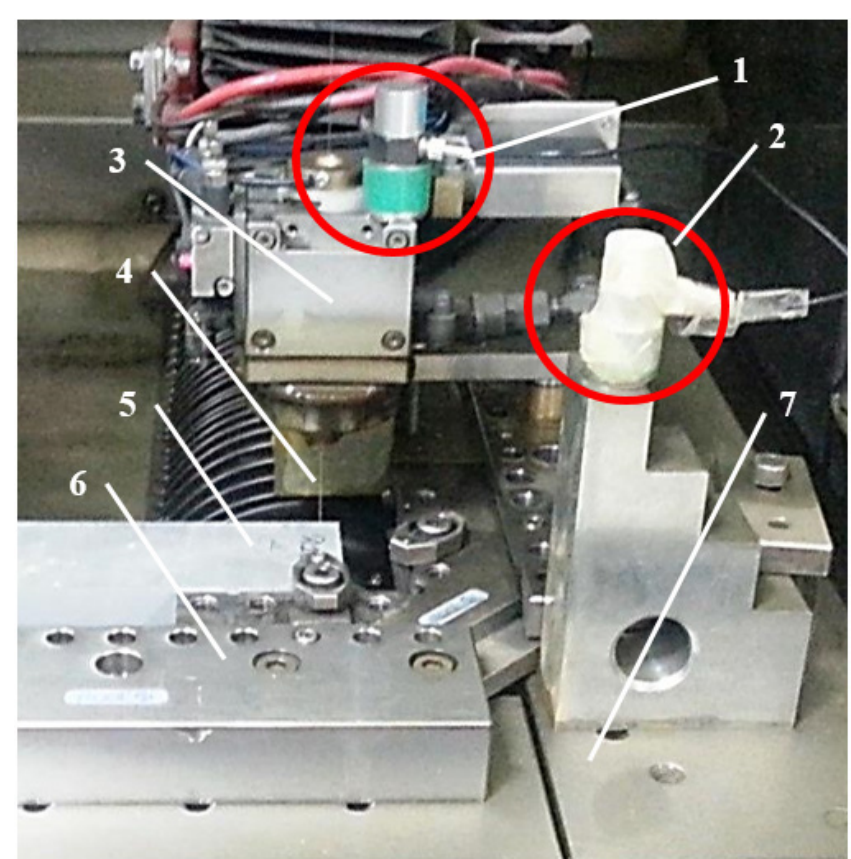

Fig. 1. Experimental setup: $(1,2)$ vibroacoustic accelerometers, (3) upper guide, (4) wire tool-electrode (WTE), (5) work piece, (6) fixing system, (7) work-table of EDM-machine.

For the purpose of analyzing the machining results by diagnostic methods, and collecting the required data on the WTE wear process, an operation of electrical discharge cutting of a long work-piece (having a length-towidth ratio of $5 / 1$ or more) has been chosen. One end of the work-piece has been secured at the worktable of the electrical discharge machine, while the other has been loosely arranged in the machine work zone. It was experimentally determined that it is this work-piece arrangement that gives rise to high amplitudes of vibrations during electrical discharge machining.

Depending on input factors used in the MACHINE WTE - WORKPIECE system, the self-induced vibrations of varying intensity arise. In order to obtain the detailed information on the nature of the system vibrations, the accelerometers should be firmly secured as close to the source of the vibrations (work zone) as possible.

In order to collect the data on the vibrations in the machine, the accelerometers have been arranged as close to the work zone as possible: at the top guide and at the worktable of the machine. The data have been captured at the following time intervals: a minute, $30 \mathrm{~s}$, and $5 \mathrm{~s}$ before the end of the machining.

The process engineers usually specify up to sixteen main parameters (main input factors) of electrical discharge machining, which influence the output measured parameters of electrical discharge machining and consequently the functionality of the end product (Fig. 2) [12]. The nature of the electrical discharge machining pulses is characterized by such factors as:

- operating voltage in the inter-electrode volume,

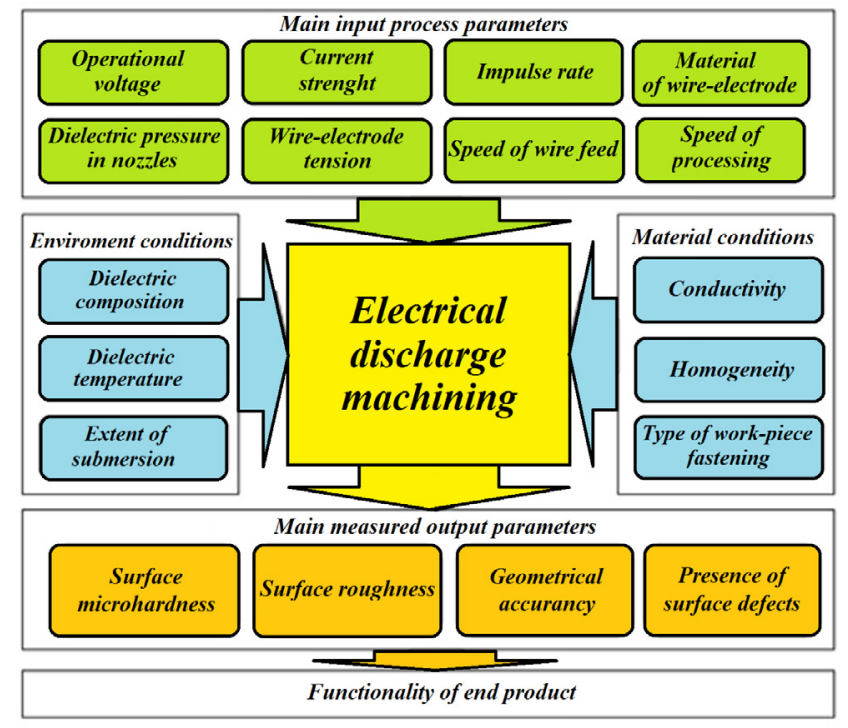

Fig. 2. Dependences of main input process parameters and main measured output parameters.

- strength of principal and auxiliary currents, frequency and duration of electrical pulses,

- tension of the wire tool-electrode, pressure of dielectric in the nozzles,

- wire-electrode rewind speed (speed of the wire toolelectrode (WTE) replacement),

- speed of forward advancement of the WTE into the machining zone, etc.

It has been determined that changing the electrical discharge machining (EDM) operation factors influences the nature and stability of the technological process, which may result in excessive wear of the WTE and the its premature breaking during operation.

In case of conical four-axis electrical discharge cutting, the break of the wire along the trajectory of its travel makes it practically impossible to restart the machining from that point, because the machine is unable to automatically insert the wire in case of inclined arrangement of the nozzles. It is necessary to move the tool to the initial wire entry point according to the control program, to insert the wire, and return to the location of break. During idle traveling along the conical path, the WTE may break again, thus the wire reinsertion operation is repeated many times, which increases the operation time. The operator has to reset the machining in the CNC system and restart the control program from the very beginning. The re-traveling of the WTE along the profile, which has already been machined, leaves additional electrical discharge mark affecting not only the visual characteristics of the surface but also the geometrical accuracy. However, at the stage of cutting the wire into the "body" of the work-piece, another break may occur at the break point after the idle traveling of the WTE. Even if the operator is able to move the WTE to the location of the break accurately and to resume seamlessly the machining process, a thermal mark will be left at the place of addi- 
S.N. Grigoriev et al.: Mechanics \& Industry 17, 717 (2016)

Table 1. Chemical composition of stainless steel 12Kh18N10T (analogue AISI 321), in \%.

\begin{tabular}{cccccccccc}
\hline & \multicolumn{1}{c}{ GOST $5632-72$} & & \\
\hline C & Si & Mn & Ni & S & P & Cr & Cu & Ti & Fe \\
\hline Up to 0.12 & Up to 0.8 & Up to 2 & $9-11$ & Up to 0.02 & Up to 0.035 & $17-19$ & Up to 0.3 & $0.4-0.8$ & About 67 \\
\hline
\end{tabular}

Table 2. Chemical composition of aluminum alloy D16, in $\%$.

\begin{tabular}{|c|c|c|c|c|c|c|c|c|c|c|}
\hline \multicolumn{11}{|c|}{ GOST 4784-97 } \\
\hline $\mathrm{Fe}$ & $\mathrm{Si}$ & $\mathrm{Mn}$ & $\mathrm{Cr}$ & $\mathrm{Ti}$ & $\mathrm{Al}$ & $\mathrm{Cu}$ & $\mathrm{Mg}$ & $\mathrm{Zn}$ & $\mathrm{Ti}+\mathrm{Zr}$ & Other admixtures \\
\hline Up to 0.5 & Up to 0.5 & $0.3-0.9$ & Up to 0.1 & Up to 0.15 & $90.9-94.7$ & $3.8-4.9$ & $1.2-1.8$ & Up to 0.25 & $<0.2$ & $\begin{array}{c}\text { Each one }-0.05 \\
\text { totally }-0.15\end{array}$ \\
\hline
\end{tabular}

tional cutting-in of the WTE into the work-piece. That is why any breaks of the WTE during precision machining are unacceptable or undesired.

For the experimental purposes, two input factors were varied: the operating voltage (from 55 to $65 \mathrm{~V}$ in increments of $5 \mathrm{~V}$ ), and the tension of the WTE (from 30 to $40 \mathrm{~N}$ in increments of $5 \mathrm{~N}$ ). Two specimen materials have been chosen for study: stainless steel 12Kh18N10T (analogue AISI 321) and aluminum alloy D16 (Tabs. 1, 2).

The material was chosen based on the rationale that the most common application of modern multi-axis electrical discharge machining is the production of shaping parts of press molds. Oftentimes, an AISI 321 material is used for production of such parts. The $12 \mathrm{Kh} 18 \mathrm{~N} 10 \mathrm{~T}$ steel may be considered as domestic analogue of this material. The aluminum alloy was chosen for study the influence of the work-piece weight on the nature of vibrations during electrical discharge machining. The dimensions of the used work-pieces were $200 \times 20 \times 16 \mathrm{~mm}$. During machining, the cutting of the samples was performed at alternating intervals of 2 and $10 \mathrm{~mm}$. The program for the machine's CNC system was written by manual input method and without consideration of compensation of the tool travel trajectory for the diameter of the wire, and the inter-electrode volume.

Seibu M-500S four-axis electrical discharge machine was used for experimental works (Tab. 3). In the capacity of the WTE, a brass wire with a diameter of $0.25 \mathrm{~mm}$ was used.

The main input factors of the electrical discharge machining, which were used during experimentation are presented in Table 4.

The dimensional characteristics of the samples have been obtained using Brown \& Sharpe micrometer (Switzerland) having a measurement error of $\pm 2 \mu \mathrm{m}$. All obtained samples have been weighted using Mettler Toledo (EL104) laboratory balance having a measurement range of $0.0001 \mathrm{~g}$ to $120 \mathrm{~g}$, and an error of $0.0001 \mathrm{~g}$. The roughness of the surface of the samples was measured using Hommel Tester profilograph-profilometer (Germany). Technical specifications: measurement range (depending on the probe used): $8,80,800,8000 \mu \mathrm{m}$ (resolution: 1 to $1000 \mathrm{~nm}$ ); the lowest read value: $0.001 \mu \mathrm{m}$; measurement error: $2 \%$. In order to study the depletion of the chemical composition of the WTE material after electrical discharge machining, the samples were put into a mold- ing press, and then the cross-section of the samples was formed using a cutoff machine, and ground using a grinding machine. All sample-preparation equipment was of ATM Company production (Germany). In order to obtain a high-resolution image of the samples' surface and of the WTE wear, a scanning electron microscope VEGA $3 \mathrm{LMH}$ (Czech Republic) having a magnification capacity of $1000000 \times$ was used.

\section{Results and discussion}

The signals read by the accelerometers, characterizing the nature of vibrations during machining were directed to an analog-to-digital converter and recorded on a personal computer [11-13]. The spectral analysis was conducted at frequencies of up to $10 \mathrm{kHz}$. The work piece was fixed in a work piece fixation system at the worktable of the electrical discharge machine and was measured according to a program for referencing the coordinate systems of the control program. In the capacity of the probe, the wire itself was used, under a voltage lower than the operating one. When the work piece contacted the WTE, the electrical circuit closed, and the signal was sent to the machine's CNC system. The coordinate system was aligned to the corner of the work piece; the coordinate system tilt angle correction in projection was preformed based on two tangencies [6].

After determining the zero position of the coordinate system on the work piece, the WTE was moved $2-3 \mathrm{~mm}$ away from the surface of the work piece. This position of the WTE was captured as the wire entry point in the coordinate system of the machine. This was required so that, at the beginning of the machining, there was some space between the WTE and the work piece before the actual cutting of the WTE into the "body" of the work piece. If the WTE is positioned too close to the work piece, upon starting of the program, the contacting occurs instantly resulting in a short-circuiting (SC). SC is highly undesirable during EDM, as it may result in a break of the wire tool-electrode, and a thermal defect on the machined surface of the work piece [20].

Before starting the machining, the work piece was immersed into dielectric and kept therein for $10 \mathrm{~min}$. The height of dielectric in the work tank of the machine was recorded to be $1-2 \mathrm{~mm}$ above the work piece level. This 
S.N. Grigoriev et al.: Mechanics \& Industry 17, 717 (2016)

Table 3. Main parameters of Seibu M-500S four-axis electrical discharge machine.

\begin{tabular}{cc}
\hline Main parameters & Value \\
\hline Max. axis travel $X \times Y \times Z(\mathrm{~mm})$ & $500 \times 350 \times 310$ \\
Max. angle of machining (degree) & \pm 10 \\
\hline Max. weight of work-piece $(\mathrm{kg})$ & 800 \\
Positioning accuracy $(\mu \mathrm{m})$ & $\pm 1-2$ \\
Roughness $R a(\mu \mathrm{m})$ & 0.4 \\
Dielectric & Deionized water \\
Description of machine stand & Stand is produced from graphite iron \\
& and has good thermo- and vibrocompensating parameters \\
\hline
\end{tabular}

Table 4. Main parameters of the processing for the experiments.

\begin{tabular}{rc}
\hline Description & Value, standard unit \\
\hline Vî, voltage in an interelectrode space before approach of WET and a work-piece & $50-60$ \\
Vg, voltage in the moment of discharge between WET and a work-piece & 32 \\
I, current strength in an interelectrode space & 8 \\
Ns, auxiliary current strength for improving of cutting efficiency during reverse close-in & 43 \\
Off, period of current source disconnexion, percentage of discharge impulse time by its absence & 6 \\
Ad, period of interimpulse pause for obtaining of processing stability & 305 \\
Ws, speed of forward feeding of WET into a work zone & 35 \\
Wt, tension force of WET & $30-40$ \\
Fl, pressure of dielectric in nozzles & 245 \\
\hline
\end{tabular}

time of pre-machining immersion of the work piece in the dielectric is required in order to balance out the temperature of the dielectric and the work piece in the work zone of the machine to avoid thermal deformation of the work piece during subsequent machining [21].

The upper guide holding the WTE in a vertical position was positioned as close to the work zone as possible, 1-2 mm from the dielectric level. As closer the upper guide is positioned to the work zone, the more precise is the cutting of the work piece (especially in case of an inclined/conical cutting).

During experiments, it has been found that the vibroacoustic signal intensifies about $10 \mathrm{~s}$ before the end of the operation (the fall-off of the work piece). The size and the weight of the cutwork piece definitely influence this parameter. As the result, the recording was performed $60 \mathrm{~s}$ before the end of the operation at each transition. The signal changes characteristic for brittle and subsequent plastic fracture of the bridge holding the work piece being cut off and the work piece together, at the upper guide, started $5 \mathrm{~s}$ before the end of the operation. The working experience has shown that this conclusion is also valid for the fracture of the WTE under excessive wear during machining. All received signals were directed to the personal computer, whereon they were presented in the form of amplitude and octave spectrum.

After the first sample cuts had been conducted, it has been found that the nature of the vibrations read by the accelerometer on the upper guide is more symmetric than of those read by the accelerometer located at the worktable of the machine. This indicates the absence of electric and electromagnetic noise while reading the signal from the upper guide. From this point on, the signals were read only from the top guide.

Before the end of machining and in case of a break of the WTE, a loss of machining stability was observed, accompanied by consistent and ever-increasing spikes of the signal amplitude. During cut-up of the bridge, slight signal spikes occurred. Then they recurred with a higher amplitude up to the very moment of the work piece falloff. The stages of plastic and brittle fracture of the material in the signal were determined. The data was captured in a high-frequency range $(8 \mathrm{kHz})$. At the stage of plastic fracture of the bridge of the work piece, the hanging work piece may deform in such a manner, that the WTE was immovably blocked between the fixated work piece and the work piece breaking off. In this case, SC occurs which causes the break of the wire tool electrode due to its blocking and impossibility of rewinding it between the guides for replacing it in the work zone as required. A machining defect in the form of a thermal burn mark forms on the surface of work piece.

During the experiment, it has been noted that at a frequency of $8 \mathrm{kHz}$, the signal amplitude $30 \mathrm{~s}$ before the end of the machining and the signal amplitude on the last second of the machining differs by more than four times (on the last second of the machining, the amplitude is four times higher than the one read $30 \mathrm{~s}$ before the end of the machining or during the "stable" cutting period). This data illustrates the importance of vibroacoustic diagnostics and on-line monitoring of the electrical discharge machining. This may serve as a basis for developing the methods of continuous vibroacoustic monitoring of the electrical discharge machining for the prevention of such 
negative effects of machining as a short-circuiting of the WTE with the work piece, uncontrolled falling of the work piece at a moment of its detachment from the work piece, etc., which in turn result in mechanical and thermal defects of the machined surface affecting the functionality of the end product.

The spikes in the amplitude during electrical discharge machining may also indicate the instability of the interelectrode space, related to an excessively intense machining mode (when the WTE is advanced forward according to the program, while the space for its movement into the "body" of the work piece has not formed yet, or the WTE rewind speed is so low that there is not enough time to replace the worn wire tool-electrode in the work zone), or with a non-uniform structure of the material (when there are "inclusions" of a component having a different electrical conductivity, or pores, craters, air bubbles in the material, this is also true for cutting of such products like "sets of hollow tubes"). In any case, the instability of the EDM results in unsatisfactory quality of the machined surface of the work piece.

During the conducted experiments, is has also been found that the tensioning of the WTE significantly affects the nature of vibrations during EDM. Because it was the main of the varied parameters of the experiment, with a variation range of $\pm 15 \%$. The amplitude of the vibrations grows as the force of tensioning of the WTE increases. Clearly, the higher tension of the wire will positively influence the results of the vibroacoustic monitoring of the EDM process. At that, in case of a $15 \%$ increase in tensioning of the WTE, a stable electrical discharge cutting of the work piece was observed. However, in case of a further increase in the force of tensioning of the WTE to $30 \%$, which was obtained during preliminary experiments, the stable cutting process was not observed. The WTE broke every time it was moved to the profile by the program.

During further study, the obtained samples were measured and weighted. By measuring the samples, it was found that the spark gap for the $12 \mathrm{Kh} 18 \mathrm{~N} 10 \mathrm{~N}$ material was $170 \mu \mathrm{m}$, and for the D16 aluminum alloy - $196 \mu \mathrm{m}$.

The obtained vibroacoustic signals were analyzed for correspondence to the roughness of the samples at the sections of the work pieces, corresponding to the time of vibroacoustic signal capturing. It was found that the amplitude spikes sections at the stage of plastic and brittle fracture of the bridge match each other at every stage of cutting of the samples according to the program. It was also found that the SC sections in the amplitudefrequency characteristic (AFC) plot correspond to the spots of thermal defects of the surface caused by blocking of the WTE between the work piece and the processing product. The decision-making time for development of vibroacoustic monitoring method for diagnosing the condition of the WTE was determined. For this type of operation, in case of the work piece weight of 5 to $25 \mathrm{~g}$, the time for making the decision of continuing the machining of the work piece amounted to 8-9 s. The stage of irreversible fracturing of the bridge starts $5-6$ s before the end of the machining, which corresponds to $0.4 \mathrm{~mm}$ of machined surface for $12 \mathrm{Kh} 18 \mathrm{~N} 10 \mathrm{~T}$ stainless steel samples.

During machining, a significant (12-15\%) increase of the vibrations amplitude values was observed at a frequency of $8 \mathrm{kHz}$ when cutting-up the final bridge, which depended on the weight of the cut-off work piece for both materials (the weight of the $12 \mathrm{Kh} 18 \mathrm{~N} 10 \mathrm{~T}$ steel samples' was 4.8 and $24.48 \mathrm{~g}$; the weight of the D16 aluminum alloy samples was 1.82 and $10.7 \mathrm{~g}$ ). In both cases, the spike in the amplitude was observed $5 \mathrm{~s}$ before the end of the machining. $30 \mathrm{~s}$ before the end of the machining, the AFC was stable.

For study the WTE wear surface, the wire samples before and after the work piece machining were examined using scanning electron microscope (SEM) (Figs. 4, 5).

Figures 3a, 3b shows the WTE before the machining. The wire tool-electrode has a round cross-section, there are mechanical marks left after manufacturing and transporting of the wire, present on the cylindrical surface of the WTE. Figure 3c shows the cross-section of the WTE after machining. It is possible to distinguish rather clearly for surfaces of the WTE, one of which has obviously been subjected to wear, and one remains untouched. Figure 3d shows the front-face (frontal) wear of the WTE. There are marks of multiple molten pools forming with each current pulse, present on the surface. Drops of solidified material of the WTE are arranged in an explosion-like manner and overlap each other. After momentary cooling of liquid metal, there are traces of multiple fractures present in the molten pool. It can be seen that the pulses formed randomly, rapidly, one over another. There are traces of many-time remelting of the material in the work zone. Figure 3e shows the nature of the side wear of the WTE. The borders between the front-face wear (on the right), the "unaffected" surface, which was not used in the machining (on the left) and the side (lateral) wear can be clearly seen on the wire. Obviously, the nature of the wear on the side surface is different from the nature of the frontface wear. There are also traces of thermal influence of the electrical current in the EDM present here. However, these traces are more "placid". Results of erosion of the material can be seen, but the scattering of the solidified drops of the material is not observed. Figure $3 \mathrm{f}$ illustrates the possible reason for absence of the characteristic drops after electrical discharge machining. It can be seen that the side surface of the WTE has suffered no only thermal but also a mechanical wear. Multiple scratches and chafe marks are present. Obviously, the molten pools caused by the influence of the electric current on the side surfaces of the WTE formed less intensively than on the front surface. After forming and solidification thereof, the surface of the WTE suffered mechanical wear caused by movement of the wire along the trajectory of the cut according to the program at idle run (between the series of pulses) and by continuous mechanical rewinding of the WTE.

Figure 4 demonstratively shows the nature of wear during EDM, obtained by performing a preliminary analysis of the SEM images. During rough machining, the 

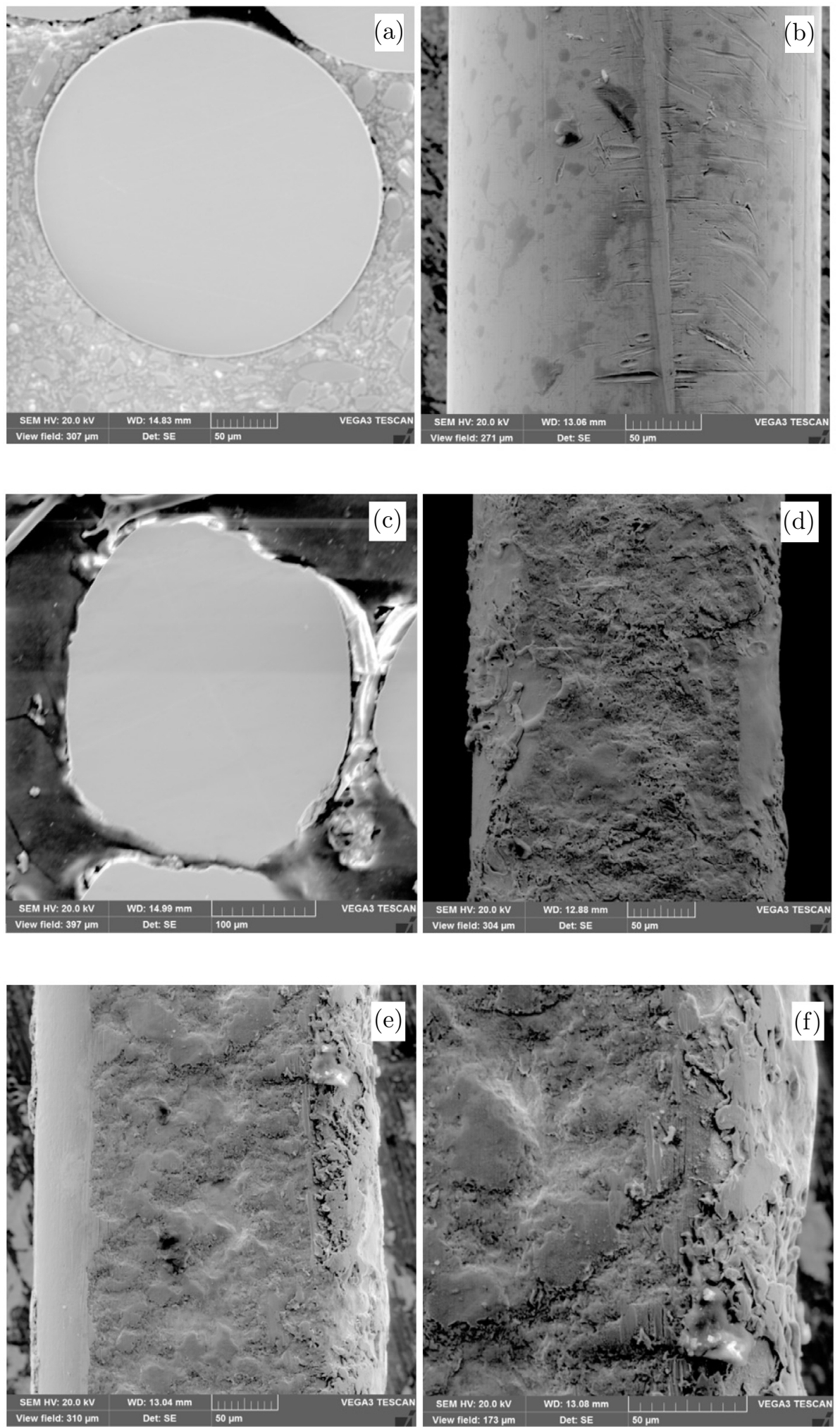

Fig. 3. SEM-images of WET: (a) cross-section of WET before processing; (b) view of the cylindrical surface of WET before processing; (c) cross-section of WET after processing; (d) view on the frontal surface of WET wear; (e) view on the lateral surface of WET wear; (f) view on the conjugation of two surfaces of WET wear: frontal and lateral. 


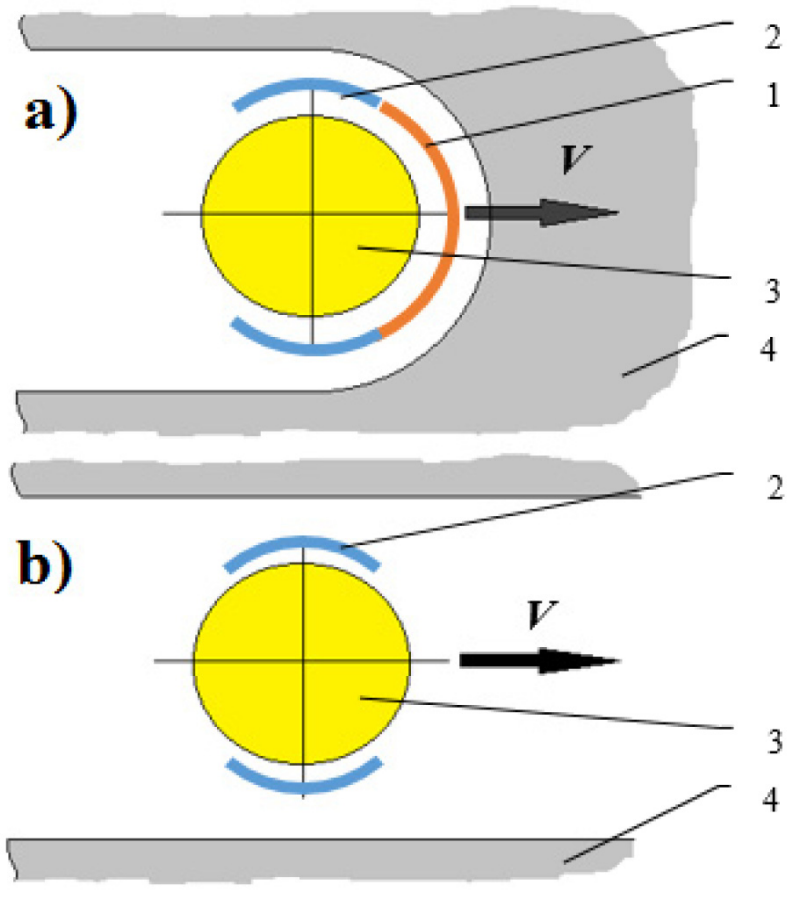

Fig. 4. Characterization of WTE wear during EDM for rough (a) and final (b) cut, where (1) is a frontal wear on the way of WTE travel during rough cut; (2) is a lateral wear; (3) is a WTE (cross-section, top view); (4) is a processing (cutting) work piece (top view); V - direction of WTE feed.

WTE is cut into the body of the work piece with the front surface of the WTE being the primary surface for machining, and the side surfaces are secondary and just help to form the surface of the cut. During the electrical discharge cutting, three of the four machining surfaces of the WTE are used. The finishing modes of the EDM are used for retraveling along the machining surface, which have already been formed. If a cut is made with a certain depth, two side surfaces of the WTE are involved in the forming of the cut walls, while the front surface is not used. In case, when the cutting-off or the cutting-out of the work piece is complete, i.e. it is performed all the way down, the scrap drops off of the work piece, with the work piece remaining fixated in the fixation system of the machine, the finishing machining is preformed using one side surface of the WTE, and the other surfaces of the WTE are not used.

Figure 5 shows the results of the chemical analysis of the WTE samples before and after the electrical discharge machining, obtained using the SEM. The analysis showed that the chemical composition of the brass wire after machining remains unchanged. After erosion, there is insignificant presence of such elements as $\mathrm{O}, \mathrm{C}$, $\mathrm{Si}$, which is so low that it cannot be shown in the diagram. The presence of such elements may be explained by the chemical composition of the dielectric and the resin for casting the samples. The dilution of the WTE material has not been observed. During the chemical analysis of the samples obtained during the experiment, it was found that the chemical elements present in the material of the WTE penetrate the "body" of the work piece to a depth of $4 \mu \mathrm{m}$, with the chemical elements corresponding to the chemical composition of the work piece material (in this case $\mathrm{Fe}, \mathrm{Cr}, \mathrm{Ni}$ for the $12 \mathrm{Kh} 18 \mathrm{~N} 10 \mathrm{~T}$ material, and aluminum for the D16 material) being washed out of the "body" of the work piece to the same depth. Such difference in the composition of the WTE and the obtained work piece samples after machining may be explained by the fact that the electro erosion processes (the processes of erosion of the material under influence of the electric current) occur less intensively on the surface of the work piece than on the surface of the WTE. Otherwise, there is no technological mean and application of the electrical discharge machining process.

\section{Conclusions}

In the course of the work, a comprehensive study of the process of wearing of the WTE during electrical discharge machining operation has been conducted. For these purposes, a vibroacoustic setup has been developed, which allowed obtaining the data on the nature of the physical processes occurring during electrical discharge machining; determining the extent of the chosen machining factors influence on the stability of the electrical discharge machining process, the nature of the vibrations in the work zone that proceeded the fall-off of the work piece and/or the break of the WTE; specifying the decision-making time for the subsequent development of the diagnostic system for monitoring the electrical discharge machining process.

The SEM images has been examined in detail for determining the nature of wearing of the WTE. Two main types of wear occurring during the EDM have been determined: thermal wear and mechanical wear. The typical surfaces of the EDM wear have been determined and classified: front-face (frontal) and side (lateral) wear during rough machining; side (lateral) wear during finish machining. The chemical analysis of the cross-sections of the WTE samples performed for the purpose of determining the electro erosion "dilution" of the material, has shown that there was no actual "dilution" of the material of the wire, however, the chemical elements of the material itself have been "washed out" from the surface of the material of the samples to a depth of $4 \mu \mathrm{m}$, while the chemical elements corresponding to the material of the WTE penetrated the material of the work pieces to the same depth.

Acknowledgements. This work has been financed by the Ministry of Education and Science of the Russian Federation in the frame of governmental task in the field of scientific activities (task order No. 9.1188.2014/K).

The work is carried out on the equipment of the Center of collective use of MSTU "STANKIN". 
S.N. Grigoriev et al.: Mechanics \& Industry 17, 717 (2016)

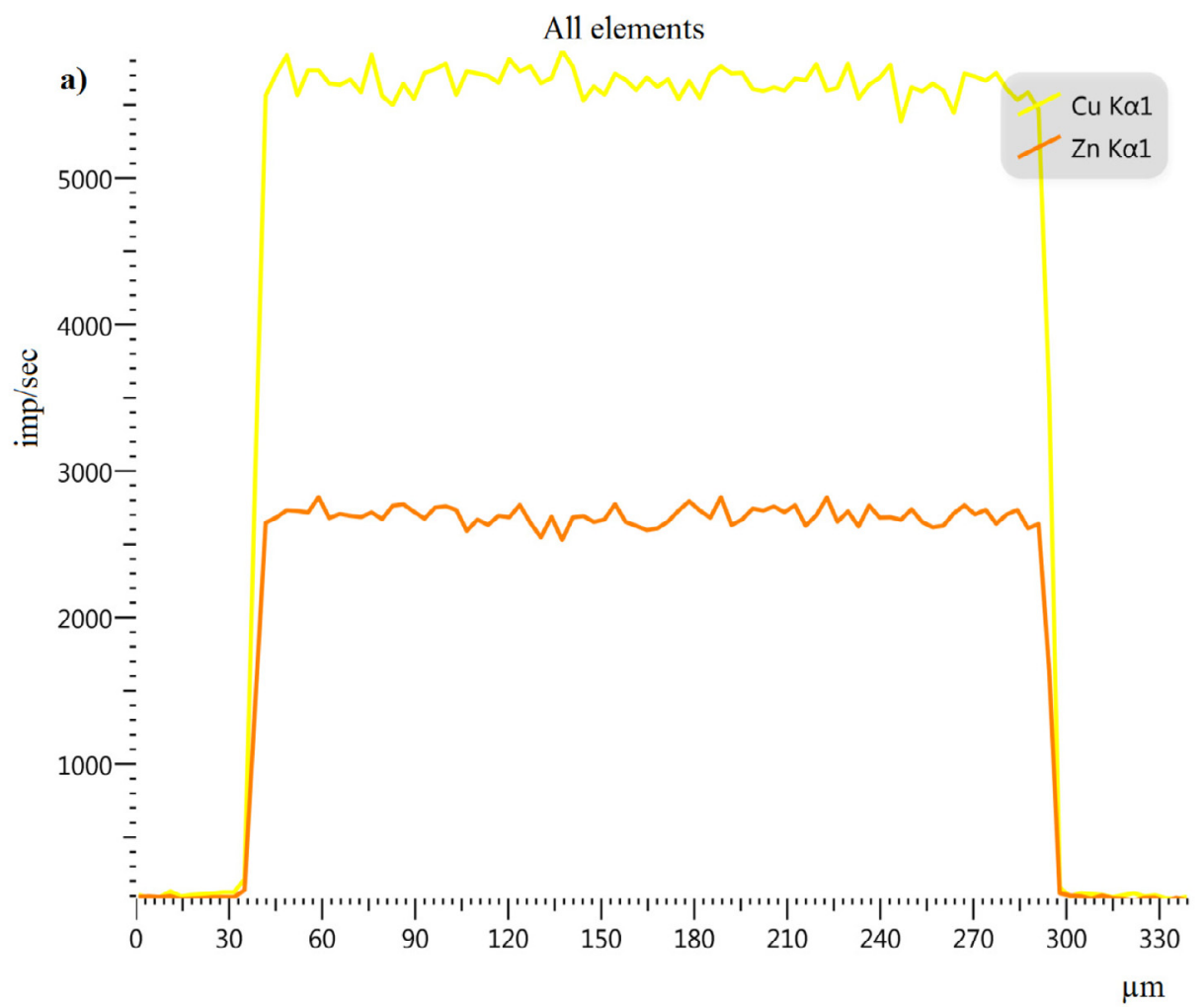

All elements

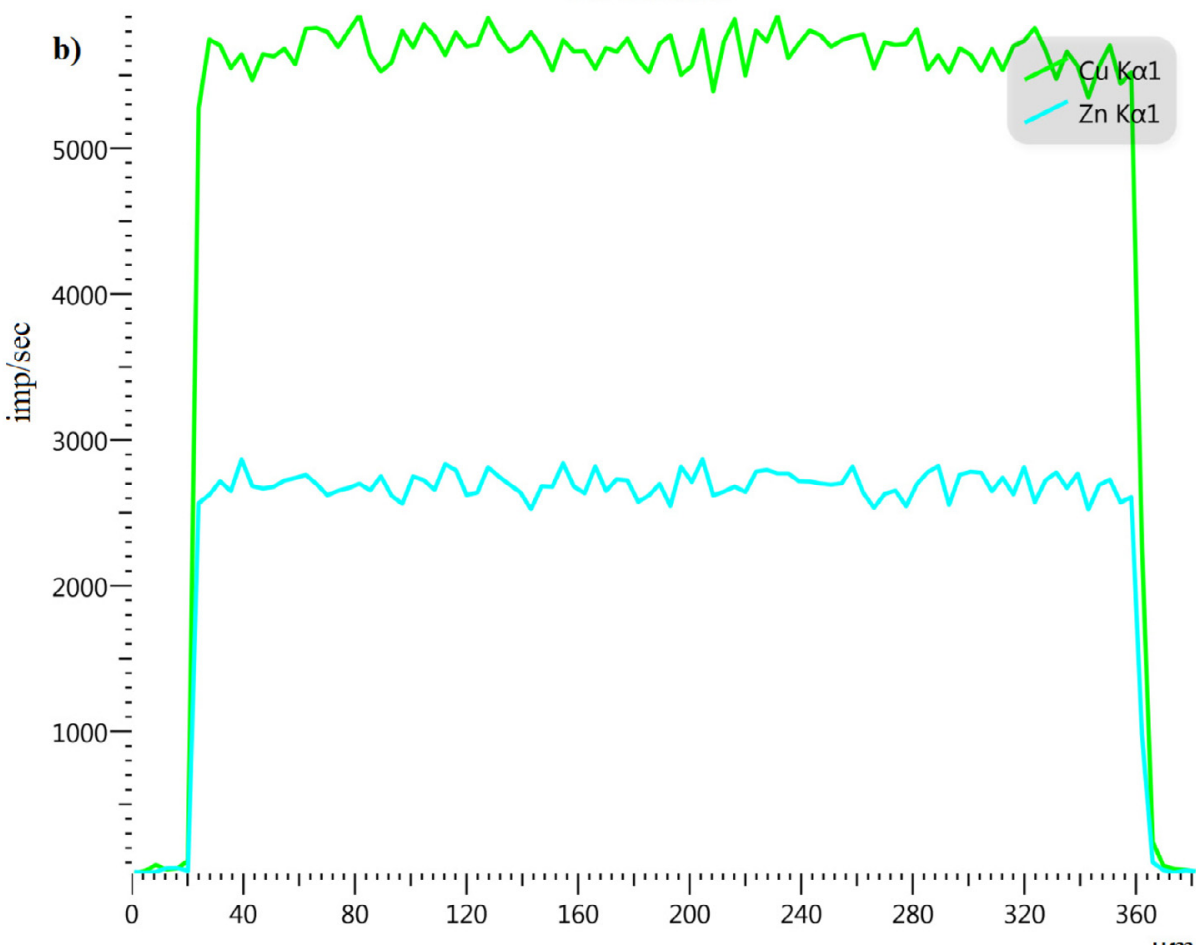

Fig. 5. The results of chemical analysis of WTE cross-section by SEM: (a) is a new wire tool-electrode; (b) is a wire tool-electrode with the marks of wear after processing. 


\section{References}

[1] F. Han, Li. Chen, D. Yu, X. Zhou, Basic study on pulse generator for micro-EDM, Int. J. Adv. Manuf. Technol. 335 (2007) 474-479

[2] N. Ojha, F. Zeller, C. Mueller, H. Reinecke, Analyzing the Electrical Pulses Occurring during EDM of NonConductive Si3N4 Ceramics, Key Eng. Mater. 651-653 (2015) 659-664

[3] A. Centeno, V.G. Rocha, B. Alonso, A. Fernández, C.F. Gutierrez-Gonzalez, R. Torrecillas, A. Zurutuza, Graphene for tough and electroconductive alumina ceramics, J. Eur. Ceramic Soc. 3315 (2013) 3201-3210

[4] S.N. Grigoriev, M.P. Kozochkin, F.S. Sabirov, A.A. Kutin, Diagnostic Systems as Basis for Technological Improvement, Procedia CIRP: Fifth Cirp Conference on High Performance Cutting. 1 (2012) 599-604

[5] H.-P. Schulze, Problems of the processing accuracy for electro-erosion and electro-chemical machining processes, Int. J. Mater. Forming 2 (2009) 641-644

[6] M.A. Volosova, A.A. Okunkova, D.E. Povolotskiy, P.A. Podrabinnik, Study of electrical discharge machining for the parts of nuclear industry usage, Mechanics Industry 167 (2015) 706

[7] A.N. Porvatov, M.P. Kozochkin, S.V. Fedorov, A.A. Okunkova, About possibility of vibroacoustic diagnostics of electrical discharge machining and characterization of defects, Mechanics Industry 167 (2015) 707

[8] A. Centeno, V.G. Rocha, B. Alonso, A. Fernández, C.F. Gutierrez-Gonzalez, R. Torrecillas, A. Zurutuza, Graphene for tough and electroconductive alumina ceramics, J. Eur. Ceram. Soc. (33) (2013) 3201-3210

[9] N. Taniguchi, Current Status in, and Future Trends of, Ultraprecision Machining and Ultrafine Materials Processing, CIRP Annals - Manuf. Technolo. 322 (1983) $573-582$

[10] V.V. Molodtsov, A.A. Okunkova, P. Yu Peretyagin, Manufacture of graphite electrodes for the electrospark machining of complex high-precision components, Russian Eng. Res. 327 (2012) 550-552

[11] M. Kozochkin, A. Porvatov, F. Sabirov, Vibration Testing of Technological Processes in Automated Machining Equipment, Measurement Techniques 5612 (2014) 1414-1420
[12] S.N. Grigor'ev, M.P. Kozochkin, S.V. Fedorov, A.N. Porvatov, A.A. Okun'kova, Study of Electroerosion Processing by Vibroacoustic Diagnostic Methods, Measurement Techniques (2015) 878-884

[13] T. Masuzawa, H.K. Tönshoff, Three-dimensional micromachining by machine tools, CIRP Annals - Manuf. Technol. V 462 (1997) 621-628

[14] M. Benedetti, D. Bortoluzzi, C. Zanoni, Non-linear Mechanical Behaviour of Metallic Micro-wires under Dynamic Axial Loads, Experimental Mech. 523 (2012) 215-228

[15] B. Mei, J. Lucas, S. Holé, I. Lamarque, N. Chéron, Excitation Mode Influence on Vibrating Wire Sensor Response, Experimental Mech. 562 (2015) 331-338

[16] M. Kozochkin, A. Porvatov, Effect of adhesion bonds in friction contact on vibroacoustic signal and autooscillations, J. Friction and Wear 355 (2014) 389-395

[17] M.P. Kozochkin, A.N. Porvatov, F.S. Sabirov, Vibration Testing of Technological Processes in Automated Machining Equipment, Measurement Techniques 5612 (2014) 1414-1420

[18] M.P. Kozochkin, A.N. Porvatov, Estimation of Uncertainty in Solving Multi-Parameter Diagnostic Problems, Measurement Techniques 582 (2015) 173-178

[19] L. Pang, A. Hosseini, H.M. Hussein, I. Deisab, H.A. Kishawy, Application of a new thick zone model to the cutting mechanics during end-milling, Int. J. Mech. Sci. 96-97 (2015) 91-100

[20] A. Okunkova, P. Peretyagin, A. Seleznyov, S.V. Fedorov, M. Kozochkin, Characterization of materials' defects after electrical discharge machining and research into their technological parameters using vibroacoutstic diagnostics, Adv. Mater. Lett. 77 (2016) 100-150

[21] A. Mohammadi, A.F. Tehrani, A. Abdullah, Investigation on the effects of ultrasonic vibration on material removal rate and surface roughness in wire electrical discharge turning, Int. J. Adv. Manuf. Technol. 705 (2014) 1235-1246 